\title{
Research on Innovation of Real Estate Marketing Model Based on Mobile Internet
}

\author{
Yan Yang \\ Chengdu Polytechnic, Sichuan, Chengdu, 610000
}

Keywords: mobile Internet; real estate; marketing model; innovation

\begin{abstract}
The development and wide application of mobile Internet technology has had an important impact on all walks of life in society. One of them is the real estate industry. Under the application of mobile internet technology, there have also been some changes in the real estate marketing model. How to combine the application of mobile Internet technology to explore a new marketing model has become a key concern of real estate practitioners, and further innovation in the real estate marketing model has also been highly valued. This paper starts with the problems of real estate marketing model under the background of mobile internet technology, and studies the measures of innovative real estate marketing model, and strives to provide more ideas for the active development of real estate marketing.
\end{abstract}

\section{Introduction}

With the adjustment of the real estate market by Chinese government departments, the demand for high-quality real estate has increased significantly in the context of the further improvement of the quality of life of the general public. To a certain extent, China's current traditional real estate marketing model has been unable to compete with the new era. The job needs are adapted, and the diverse needs and individualized needs of the public in real estate projects cannot be met. Based on this, under the influence of the mobile Internet era, it is necessary to strengthen the integration of mobile Internet technology and real estate marketing work, actively explore the measures of real estate marketing model reform and innovation, actively and effectively play an important role in the innovative real estate marketing model, and support real estate enterprises.

\section{The Problem in China's Real Estate Marketing Model Based on Mobile Internet}

Based on the analysis of the basic situation of China's real estate marketing under the impact of mobile Internet, it is found that the management of real estate enterprises in China has gradually realized the importance of reforming and innovating the real estate marketing model, combined with the real estate marketing model. Reform and innovation have been properly explored, and strive to provide corresponding support and guarantee for the construction of marketing model [1]. However, it should be noted that in the process of actually carrying out real estate marketing activities, the marketing model still has obvious problems, and it is unable to adapt to the actual needs of organizing real estate marketing work in the new period.

The development of the real estate industry needs to rely on the necessary market research to locate the consumer groups, so as to make accurate marketing strategies to attract consumers. However, the application of mobile Internet technology, real estate companies rely on the network to release marketing information, although the speed of communication has been greatly improved, and is not fastened to consumers by time and space restrictions, but network marketing is unidirectional, whether this information can be received by the Internet audience There is still a problem with further attention and whether the company's online marketing strategy is in line with real consumer demand. Based on the lack of detailed market research on consumers in the online market, development companies cannot obtain accurate market information, so they cannot accurately locate online consumers, blindly describe the characteristics of target customers according to their own will, and thus develop a lack of market demand. Personalized and diversified 
online marketing strategy.

In order to highlight the actual effect of marketing work in the development process of real estate enterprises, we also tried to systematically research the construction of marketing channels based on the application of mobile internet technology, hoping to open up diversified marketing channels and comprehensively enhance the marketing work of real estate enterprises [3]. Specific analysis, the problems in the construction of real estate enterprise marketing channels are concentrated in the following aspects: the construction activities of real estate projects are lack of professionalism, and the marketing activities have not been properly organized in combination with real estate enterprises and related consumers. Marketing information the transmission is not smooth, resulting in huge consumption costs, affecting the actual effect of marketing work; the connection between the marketing channel through the fixed sales store and the mobile Internet marketing decision-making model is not close enough, and the actual organization of the marketing work cannot be realized. The organic combination of the people will seriously restrict the expansion of marketing channels and the construction of diversified marketing models. It can be seen that in the process of real estate enterprises organizing marketing activities, the construction of marketing channels lacks rationality, and it is difficult to gradually realize diversified marketing, which will also affect the comprehensive development results of marketing work.

In the process of real estate companies organizing marketing activities, the design and planning of promotional strategies will have a direct impact on marketing effectiveness. Combining with the background of mobile internet to analyze the current promotion work, it is found that the traditional promotion strategy formulated by real estate enterprises in combination with their own development needs is not innovative enough to attract consumers' attention, and even cause consumers to form promotional immunity, which causes serious problems in the promotion of promotional activities. At the same time, in the process of organizing real estate promotion activities, the current sales performance is still guided by the promotion activities, and the formulation of the promotion organization strategy will seriously hinder the long-term marketing ability and the improvement of long-term marketing profit, and will also promote the promotion. Organizational optimization of work has a negative impact. Therefore, it is necessary to study the design and planning of the promotion strategy in the new era, formulate a more scientific promotion organization plan, and accelerate the development of the marketing work of real estate enterprises [4].

In the development process of real estate enterprises, due to the lack of correct understanding of the importance of brand building in marketing, the precise positioning of the marketing activities was not carried out, and the brand construction effect was not satisfactory. Although most real estate companies have tried to combine the mobile Internet technology to explore the construction of marketing platform in combination with their own interests, but in the absence of systematic theoretical guidance and scientific planning, there is no successful development, and the effectiveness of real estate marketing under the support of mobile Internet technology is insufficient. [2]. Analysis of the current mobile Internet marketing activities carried out by real estate companies, found that some real estate marketers through the opening of WeChat and Weibo account, the release of humor and inspirational articles attracted a large number of fans to achieve real estate-related projects marketing. However, fans and followers attracted by this marketing model have low attention to real estate projects, unable to achieve effective marketing, brand construction effects are not ideal, marketing efforts and marketing influence are insufficient.

\section{The Innovative Development Strategy of Real Estate Marketing Model Based on Mobile Internet}

Based on the research on the actual situation of real estate enterprise marketing in the context of mobile internet technology, it is found that in order to improve the marketing effect with the support of Internet technology, it is necessary to explore the organic connection between mobile Internet technology and real estate marketing model innovation, and then make scientific and reasonable. The marketing organization plan, under the support of the innovative concept, scientifically optimizes the marketing work effect, ensures that the innovative development trend of real estate 
marketing work can be formed, and comprehensively highlights the comprehensive development results of marketing work [5].

Internet marketing in the Internet era also requires full market research. Managers of real estate enterprises need to formulate new market research plans based on the characteristics of the network era, build a network platform to carry out rich network marketing activities, improve customer participation awareness, and strengthen enterprises and consumption. The connection and communication between the two, changing the way of traditional marketing information one-way communication, becoming a two-way interaction between the enterprise and the consumer, realizing interactive marketing, such as launching a network questionnaire, or a prize-winning activity, etc. The exchanges to obtain consumers' consumption characteristics and purchase intentions, on this basis, real estate companies can make accurate market positioning, determine the type, function, and even price of their products. At the same time, through better market positioning, network marketing means can be more rich and targeted. The marketing media audience can design promotional content according to the preferences of real estate products, enhance product selling points, attract customers' attention to products, and at the same time pass The online platform facilitates timely communication and can quickly understand the marketing effect and optimize the marketing model. Finally, establish a good customer feedback mechanism, collect customer opinions through the mobile network platform, and further understand consumer needs, thereby improving real estate products and services.

The optimization of real estate mobile network marketing channels has a crucial impact on marketing effectiveness. In the new era, in the practice exploration activities of organizing real estate mobile network marketing work, in order to be able to scientifically adjust sales activities, realize effective marketing channels. To expand, we should explore the construction of mobile Internet marketing channels to ensure that real estate marketing can achieve more significant results. First of all, it is necessary to contact the marketing media audience to make appropriate adjustments to the marketing activities to ensure that the marketing information of real estate enterprises can be effectively disseminated on the network platform based on the optimization of the functions of the mobile Internet network platform. Highlight the value of network marketing channels and gradually promote the overall improvement of marketing work quality [7]. Secondly, in the process of expanding online sales channels, real estate enterprises should actively explore the construction of Weibo and WeChat marketing platforms, and give full play to the important role of new media marketing platforms such as Weibo and WeChat, so that marketing information can be in a wider range. In this way, the mobile internet marketing channel system of the system can be constructed step by step, and the influence of marketing channels on marketing work will be further enhanced, which will support and promote the acquisition of marketing benefits in the development of real estate enterprises in the new era.

Under the support and influence of mobile internet technology, real estate enterprises must strengthen the application of mobile platform in the process of exploring marketing model innovation, and adjust the promotion strategy in combination with the application of mobile platform to ensure that the relevant real estate project marketing of the enterprise can be fully explored. The advantage of work promotes the further enhancement of comprehensive influence and creates ideal conditions for the acquisition of comprehensive benefits in the marketing work of real estate enterprises. First of all, the integrated experience marketing and mobile network marketing should be organically combined, and the effective stimulation of the consumer's stimulating consumer experience and impulsive consumer desire can be realized on the basis of comprehensive application of different marketing models to ensure scientific and effective promotion work. Under the support, we can further enhance consumers' sense of identity in real estate promotion activities, and then gradually improve the actual effect of the promotion work, and lay a solid foundation for the modernization of marketing work in the development process of real estate enterprises [8]. Secondly, we must actively explore the organic combination of word-of-mouth marketing and mobile network marketing to ensure that the spontaneous communication efficiency of real estate marketing can be formed, and the potential of audience 
marketing information dissemination can be fully explored, thereby improving the actual effect of information dissemination work. In this way, we can promote the establishment of a good brand image and social image of real estate enterprises by means of the adjustment of word-of-mouth marketing strategy and the enhancement of mobile network marketing capabilities. In the process of word-of-mouth shaping and dissemination, the marketing benefits of real estate enterprises can also be appropriately deepened. It will effectively support the scientific development of real estate network marketing business and the gradual enhancement of the comprehensive marketing effect of real estate enterprises in the new era.

With the support of mobile internet technology, comprehensively organizing the innovative construction of real estate marketing model can further enhance the influence of marketing work and comprehensively highlight the comprehensive effect of marketing work. First of all, with the support of mobile Internet technology, we can properly optimize the price of brand assets by gradually constructing a good real estate brand image, and then provide corresponding support for the development of marketing work. In general, in order to be able to combine the application of mobile Internet technology and enhance the attention and awareness of the consumer group on the relevant platform of the real estate project, it is necessary to pay attention to the adjustment of the project name and advertising plan to establish a brand image, and to create a high quality. The image with good performance and dignified style attracts the attention of the audience, stimulates consumers' desire to purchase, comprehensively enhances the success rate of consumers, and creates conditions for the acquisition of mobile Internet marketing benefits of real estate enterprises. Secondly, the real estate brand is turned into intangible assets, guiding consumers' consumption concept, allowing consumers to pay for the brand, paying attention to the brand's products while paying attention to the brand, and promoting brand influence through word-of-mouth marketing. Companies can get more out of it.

\section{Conclusion}

In summary, under the mobile Internet, real estate companies have changed their internal and external environments in the process of organizing marketing activities. The traditional marketing model has been difficult to adapt to the actual marketing needs. How to combine real estate marketing with the development needs of the new era The reform and innovation of the model has become an urgent problem to be solved. Therefore, in the new era, we should also combine mobile Internet technology, strengthen the exploration of real estate enterprises to carry out marketing activities, strive to develop a more complete marketing management plan, effectively promote the orderly development of real estate network marketing business, and strive to be able to use active and effective marketing as a real estate enterprise. Create greater economic and social benefits.

\section{References}

[1] Xia Xianyu. Innovation of Real Estate Marketing Model under Mobile Internet [J]. Journal of Business Economics, 2016(8): 65-66.

[2] Wang Yindong. Research on the innovation of real estate marketing strategy in the "Internet +" era [D]. Jinan University, 2017.

[3] Xue Xiwei. Mobile Internet Marketing of Real Estate [J]. Market Weekly, 2015(2): 46-47.

[4] Li Zhuoyu. Research on real estate application software based on $\mathrm{O} 2 \mathrm{O} 2 \mathrm{O}$ in mobile internet [D]. Hunan University, 2015.

[5] Yan Wenlin. Real Estate Mobile Internet Marketing Based on User Experience [J]. Modern Marketing (Post Journal), 2016(12):81-82.

[6] Wu Qiang. Thinking on China's Real Estate Marketing Strategy Based on "Internet +"[J]. Journal of Business Economics, 2016 (18): 75-76. 
[7] Wang Da. Talking about the Library Service Innovation of the School of Administration in the Mobile Internet Age [J]. Knowledge Economy, 2018(2):175-176.

[8] Tao Houyong, Sun Weimin. Research on the innovation of engineering science and technology talent development strategy in the era of mobile internet [J]. Journal of Jiangsu University (Social Science Edition), 2018, 20(2): 55-62.

[9] Cui Wei. Research on the Innovation Model of Education Culture Promotion Based on Mobile Internet Platform [J]. 2018(1): 119-120. 